\title{
PERAN BODY-IMAGE TERHADAP PENYESUAIAN DIRI PEREMPUAN DEWASA DINI PADA KEHAMILAN PERTAMA
}

\author{
Sri Hayuningtyas Sari \\ Ade Rahmawati Siregar ${ }^{*}$ \\ Universitas Sumatera Utara
}

\begin{abstract}
ABSTRAK
Penelitian ini bertujuan untuk melihat peran body-image (penilaian individu terhadap tubuhnya) terhadap penyesuaian diri (proses adaptasi individu dalam menghadapi tantangan dalam kehidupan sehari-hari) perempuan yang mengalami kehamilan pertama. Hasil penelitian ini menunjukkan bahwa body-image memiliki peran penting bagi penyesuaian diri perempuan hamil pertama yang berusia 26-30 tahun, berstatus bekerja, dan usia kandungan berada pada triwulan ke-tiga. Individu yang menilai tubuhnya dengan tinggi cenderung memiliki penyesuaian diri yang tinggi pula.
\end{abstract}

Kata kunci: Body-image; penyesuaian diri; perempuan dewasa dini, kehamilan pertama

\section{THE ROLES OF BODY-IMAGE ON SELF-ADJUSTMENT AMONG EARLY ADULTHOOD WOMEN EXPERIENCING FIRST PREGNANCY}

\begin{abstract}
The present research was aimed to examine the roles of body-image (individuals attitude regarding his or her physical body) on self-adjustment (individual's adaptation process in dealing with life challenges) of female experiencing first pregnancy. The results suggests a significant role of body-image on female experiencing first pregnancy aged 26-30 years old, working, and and whose pregnancy is in the third trimester. Individuals with high body-image tended to have high self-adjustment.
\end{abstract}

Keywords: Body-image; self-adjustment, early adulthood women, first pregnancy * Korespondensi mengenai penelitian ini dapat dilayangkan kepada Ade Rahmawati Siregar
melalui e-mail: aderahmawati19@yahoo.co.id 
Kehamilan adalah salah satu tugas perkembangan yang didambakan oleh sebagian besar perempuan dewasa dini yang telah memasuki kehidupan berumah tangga. Menurut Kartono (1995) perempuan yang sedang hamil merasa bangga akan kesuburan, dan berbahagia menyambut kelahiran anaknya.Biasanya calon ibu akan mengembangkan mekanisme kepuasan dan kebanggaan jika kehamilan tersebut merupakan yang pertama kali, karena ia bisa memenuhi tugas kewajiban sebagai perempuan dan sebagai penerus generasi. Rasa bahagia juga timbul karena sebagian perempuan menganggap kehamilan merupakan kebanggaan sebagai wujud kesempurnaan.

Kehamilan memang membawa kebahagiaan tersendiri bagi para perempuan, tetapi tidak dapat dipungkiri bahwa proses untuk menjadi seorang ibu adalah peristiwa yang mendebarkan dan penuh tantangan (Effendi \& Tjahjono, 1999). Perempuan yang paling berbahagia dengan kehamilannya pun mengalami kekhawatiran, yang disebabkan oleh keraguan akan kemampuan untuk melewati berbagai perubahan yang terjadi dalam kurun waktu sembilan bulan dan peran baru sebagai ibu yang akan diterimanya (Astuti, Santosa, \& Utami, 2000). Pengalaman ini menimbulkan berbagai perasaan yang bercampur baur antara bahagia dan penuh harapan dengan kecemasan tentang apa yang akan dialaminya selama kehamilan, khususnya pada kehamilan pertama (Effendi \& Tjahjono, 1999).

Lanzelius (dalam Rubin, 2005) menyatakan bahwa kehamilan pertama merupakan pengalaman pembentukan kehidupan yang membawa perubahan sosial dan psikologis yang besar. Selain itu, perempuan pada kehamilan pertama belum pernah mengalami perubahan fisik yang berhubungan dengan kehamilan dan mengembangkan kemampuan kognitif yang terkait dengan perkembangan identitas keibuan. Menurut Newman dan Newman (2006), beberapa perempuan merasa sangat senang dan bersemangat menghadapi kehamilan, sedangkan yang lain mengalami simptom kecemasan dan depresi. Hal ini sesuai dengan hasil penelitian Thompson dan Tantleff-dunn (dalam Rubin, 2005) yang menemukan bahwa kebanyakan perempuan yang hamil untuk pertama kalinya hanya tahu sedikit saja mengenai proses yang terjadi pada dirinya. Pengetahuan yang kurang akan apa yang dihadapi mengakibatkan rasa cemas dan takut, sehingga masa kehamilan kurang menyenangkan.

Masa kehamilan merupakan masa dengan berbagai perubahan dalam diri seorang perempuan, karena kehamilan akan merubah hampir semua sistem tubuh seorang perempuan (Kartono, 1995). Selama kehamilan perempuan mengalami perubahan yang khas dalam segi fisik. Alexander dan Carlson (dalam Matlin, 2004) menyatakan bahwa perubahan fisik selama kehamilan meliputi payudara yang mengencang, sering buang air kecil, dan merasa lelah. Selain itu, sebagian besar perempuan menyatakan adanya kenaikan berat badan dan pembesaran pada bagian perut atau abdomen.

Sikap terhadap berat dan bentuk tubuh selama kehamilan memiliki dampak yang penting terhadap kenaikan berat badan selama kehamilan dan kesehatan mental ibu setelah melahirkan (Rubin, 2005). Sebagaimana diketahui bahwa kenaikan berat badan yang ideal pada perempuan selama kehamilan adalah sekitar 6,5 - 16,5 kilogram. Kenaikan berat badan di bawah ataupun di atas rentang tersebut akan menimbulkan masalah pada kesehatan ibu dan janin (Mochtar, 1998). Selain itu, kekhawatiran tentang berat badan dan bentuk tubuh selama kehamilan juga berhubungan dengan distres postpartum (Abraham \& Walker dalam Rubin, 2005) dan simptom depresi (US Fed News Service, 2008).

Perubahan fisik selama kehamilan berkonsekuensi terhadap perubahan body-image perempuan (Newman \& Newman, 2006). Body-image merupakan sikap yang dimiliki seseorang 
terhadap tubuhnya yang dapat berupa penilaian positif dan negatif (Cash \& Pruzinsky dalam Thompson, 1999; Robertson-Frey, 2005).

Body-image merupakan aspek penting selama kehamilan karena body-image yang positif berhubungan dengan perasaan positif terhadap kehamilan secara umum (Da Pietro dalam Rubin, 2005). Da Pietro juga menambahkan bahwa terdapat perbedaan body-image antara perempuan yang mengalami kehamilan pertama dengan perempuan pada kehamilan berikutnya. Perempuan pada kehamilan pertama lebih cemas terhadap body-image daripada perempuan pada kehamilan kedua atau ketiga. Hal ini dikarenakan perempuan yang hamil pertama kalinya belum memiliki pengalaman tentang perubahan yang terjadi selama kehamilan.

Body-image yang baik akan menjadikan seseorang memiliki konsep diri yang positif (Dacey \& Kenny, 2001). Oleh karena itu, seseorang yang memiliki kepuasan body-image diharapkan juga memiliki konsep diri yang positif, dengan konsep diri yang positif, maka seseorang akan mudah menjalani hidupnya, tampil lebih percaya diri, dan lebih asertif (Baron \& Byrne, 2000). Bagi perempuan, konsep diri secara khusus didasarkan pada body-image dan sebagai konsekuensinya, hal ini memperani fungsi sosial dan hubungan interpersonal mereka, yang pada akhirnya sangat menentukan bagaimana penyesuaian diri mereka (Newman \& Newman, 2006).

Adaptasi terhadap perubahan body-imagememiliki perngaruh terhadap penyesuaian diri dan sosial, kesejahteraan psikologis, dan perilaku sehat (Ferron, 1993). Hal ini sesuai dengan yang dikemukakan Schneiders (dalam Ali \& Anshori, 2004) bahwa body-image akan berdampak pada penyesuaian diri seseorang, yaituproses yang melibatkan respon-respon mental dan tingkah-laku untuk menghadapi kebutuhan internal, konflik, ketegangan, dan frustasi serta untuk menyelaraskan tuntutan dari dalam diri individu dengan tuntutan yang berasal dari lingkungan tempat individu berada. Masa kehamilan mengandung berbagai perubahan fisik dan psikologis, yang sesungguhnya adalah peristiwa yang normal (Astuti dkk., 2000), namun menurut Robertson-Frey (2005), banyak perempuan yang mengalami kesulitan dalam menerima perubahan pada tubuh mereka selama hamil, walaupun perubahan fisik tersebut dapat dianggap sebagai bagian yang alami dari sebuah kehamilan. Kondisi fisik ini sering menimbulkan rasa tegang, cemas dan konflik-konflik batin (Effendi \& Tjahjono, 1999). Padahal, ibu hamil yang tidak dapat menyesuaikan diri dengan kehamilannya akan kurang mampu mengatasi tekanan dan tuntutan yang ada sehingga dapat menimbulkan gejolak dalam batinnya dan kecemasan yang dialaminya akan tinggi (Effendi \& Tjahjono, 1999). Berdasarkan uraian ini, peneliti ingin meneliti apakah body-imageberperan secara signifikan terhadap penyesuaian diri perempuan dewasa dini pada kehamilan pertama.

\section{METODE}

Penelitian ini merupakan penelitian yang menggunakan pendekatan kuantitatif yang bertujuan untuk mengetahui seberapa besar peranbody-image terhadap penyesuaian diri wanita pada kehamilan pertama

\section{Definisi operasional}

\section{Body-image}

Body-image adalah evaluasi atau sikap yang dimiliki seseorang secara partisipatif terhadap tubuhnya. Evaluasi atau sikap tersebut bisa berupa perasaan suka, puas atau positif yang ditunjukkan dengan penerimaan terhadap tubuhnya atau bisa berupa perasaan tidak suka, tidak puas, atau negatif seseorang terhadap atribut-atribut fisik pada tubuhnya seperti ukuran tubuh, 
berat badan, dan bentuk tubuh. Dalam penelitian ini, body-image diukur dengan menggunakan aitem-aitem pernyataan yang disusun sendiri oleh peneliti berdasarkan dimensi-dimensi bodyimage menurut Cash (1999) yaitu evaluasi penampilan, orientasi penampilan, kepuasan area tubuh, kecemasan menjadi gemuk dan persepsi terhadap ukuran tubuh. Semakin tinggi skor partisipan penelitian dalam skala body-image, maka akan semakin baik pula body-image yang dimiliki oleh partisipan.

\section{Penyesuaian diri}

Penyesuaian diri adalah suatu proses yang mencakup respon-respon mental dan tingkah laku yang merupakan usaha individu agar berhasil mengatasi tuntutan kebutuhan, ketegangan, konflik, dan frustrasi yang dialami dalam dirinya secara matang, bermanfaat, efisien, efektif, dan memuaskan yang disesuaikan dengan tuntutan situasi yang dialami individu. Dalam penelitian ini, penyesuaian diridiukur dengan menggunakan aitem-aitem pernyataan yang disusun sendiri oleh peneliti berdasarkan karakteristik penyesuaian diri menurut Schneiders (dalam Ali \& Anshori, 2004) yaitu:

a. Mampu mengontrol emosionalitas yang berlebihan.

b. Mampu mengatasi mekanisme psikologis.

c. Mampu mengatasi perasaan frustrasi pribadi.

d. Kemampuan untuk belajar.

e. Kemampuan memanfaatkan pengalaman.

f. Memiliki sikap yang realistis dan objektif.

Semakin tinggi skor partisipan penelitian dalam skala penyesuaian diri, maka akan semakin baik pula penyesuaian diri yang dimiliki oleh partisipan.

\section{Populasi dan metode pengambilan sampel}

Populasi dalam penelitian ini adalah wanita dewasa dini yang sedang hamil pertama. Karakteristik sampel yang digunakan dalam penelitian ini adalah wanita berusia 20-35 tahun, memiliki suami, sedang hamil pertama dan tidak memiliki riwayat keguguran.Pengambilan sampel dilakukan dengan teknik incidental sampling.Jumlah sampel yang digunakan dalam penelitian ini adalah sebanyak 60 orang wanita hamil pertama dan untuk uji coba (try out)digunakan 90 orang wanita hamil.

\section{Alat ukur yang digunakan}

\section{Skala body-image}

Alat ukur yang digunakan untuk mengukur body-image adalah skala body-image yang disusun sendiri oleh peneliti. Pernyataan-pernyataan pada skala ini didasarkan pada enam dimensi body-image yang dikemukakan oleh Cash (1999). Skala ini terdiri dari 50 pernyataan, empat pernyataan untuk masing-masing dimensi. Setiap pernyataan memiliki empat pilihan jawaban yaitu Sangat Sesuai (SS), Sesuai(S), Tidak Sesuai (TS), Sangat Tidak Sesuai (STS). Penilaian skala ini bergerak dari angka 1 hingga 4 . Bobot penilaian untuk pernyataan favorable yaitu $\mathrm{SS}=4, \mathrm{~S}=3$, TS=2, $\mathrm{STS}=1$. Bobot penilaian untuk pernyataan unfavorable yaitu $\mathrm{SS}=1, \mathrm{~S}=2$, $\mathrm{TS}=3$, dan $\mathrm{STS}=4$. Total penilaian berkisar dari 50-200.

\section{Skala penyesuaian diri}

Alat yang digunakan untuk mengukur penyesuaian diri juga berbentuk skala. Skala penyesuaian diri yang digunakan dalam penelitian ini disusun sendiri oleh peneliti berdasarkan enam dimensi penyesuaian diri yang dikemukakan oleh Schneiders (dalam Ali \& Anshori, 2004). 
Skala ini terdiri dari 48 pernyataan. Setiap pernyataan memiliki empat pilihan jawaban yaitu Sangat Sesuai (SS), Sesuai (S), Tidak Sesuai (TS), Sangat Tidak Sesuai (STS).Penilaian skala ini bergerak dari angka 1 hingga 4. Bobot penilaian untuk pernyataan favorable yaitu $\mathrm{SS}=4, \mathrm{~S}=3$, $\mathrm{TS}=2$, $\mathrm{STS}=1$. Bobot penilaian untuk pernyataan unfavorable yaitu $\mathrm{SS}=1, \mathrm{~S}=2$, $\mathrm{TS}=3$, dan STS=4. Total penilaian berkisar dari 48-196.

\section{Validitas dan reliabilitas alat ukur}

\section{Hasil uji coba alat ukur}

1. Pada skala body-image,corrected-item to total correlation adalah antara 33 sampai dengan .65 dengan aitem yang memenuhi kriteria berjumlah 17 aitem. Reliabilitas alpha skala body-image adalah .93.

2. Pada skala penyesuaian diri, corrected-item to total correlation adalah antara .32 sampai dengan .70 dengan aitem yang memenuhi kriteria berjumlah 25 aitem. Reliabilitas alpha skala penyesuaian diri adalah .92 .

\section{Metode analisa data}

Sesuai dengan tujuan penelitian, teknik yang digunakan untuk menganalisa data penelitian ini adalah dengan menggunakan statistik uji analisa regresi sederhana dengan bantuan program SPSS version 16.0 for windows. Sebelum data diolah, terlebih dahulu dilakukan uji asumsi penelitian yaitu uji normalitas sebaran dan uji linearitas hubungan.

\section{HASIL}

\section{Uji asumsi}

Untuk menguji normalitas, kami menggunakan analisis statistik nonparametrik one sample $K$-S. Untuk skala body-image diperoleh nilai $z=0.73, p=.66$, hal ini menunjukkan bahwa penyebaran data penelitian pada variabel body-image adalah normal. Hasil uji normalitas pada skala penyesuaian diri diperoleh nilai $z=0.53$ dan $p=.94$, hal ini juga menunjukkan bahwa penyebaran data penelitian pada variabel ini normal. Hasil uji linearitas antara variabel bodyimage dengan penyesuaian diri dengan menggunakan uji $F$ diperoleh nilai $F=14.09, p=.001$, dengan demikian diketahui bahwa body-image memiliki hubungan yang linear dengan penyesuaian diri.

\section{Peranbody-image terhadap penyesuaian diri}

Peran body-image terhadap penyesuaian diri kami ujikan dengan melakukan analisis regresi sederhana, yang mana Body-image kami masukkan sebagai prediktor Penyesuaian diri. Hasil yang didapatkan menunjukkan ekuasi yang signifikan, $F(1,59)=14.09, \quad R=.44$, $p=.001$. Koofisien determinasi $\left(R^{2}=.20\right)$ mengindikasikan sebanyak $20 \%$ kebervariasian penyesuaian diri dapat diprediksikan oleh body-image. Hasil ini menunjukkan bahwa penyesuaian diri para perempuan dewasa dini yang mengalami kehamilan pertama meningkat seiring dengan peningkatan body-image. Dengan demikian, sesuai hipotesis yang diajukan, bodyimage berperan penting terhadap penyesuaian diri para perempuan usia dini yang mengalami kehamilan pertama. Selanjutnya, dengan mempertimbangkan konstanta $\left(b_{0}=76.61\right)$ dan kelandaian garis regresi $(b=.32)$ dalam persamaan regresi $\mathrm{Y}=b_{0}+b \mathrm{X}$, dapat diprediksikan bahwa setiap penambahan satu satuan skor body-image diikuti dengan kenaikan penyesuaian diri sebesar 76.93 . 


\section{Hasil tambahan}

Body-image berperan secara signifikan terhadap penyesuaian diri wanita dewasa dini pada kehamilan pertama pada kelompok usia 26-30 tahun, $R^{2}=.78, p=.001$. Sedangkan pada kelompok usia 20-25 tahun $(p=.43)$ dan usia 31-35 tahun $(p=.06)$, hubungan peran bodyimage terhadap penyesuaian diri tidaklah signifikan. Body-image berperan secara signifikan terhadap penyesuaian diri pada kelompok partisipan yang bekerja, $R^{2}=.46, \quad p=.001$. Sedangkan pada kelompok partisipan yang tidak bekerja, peranbody-image terhadap penyesuaian diri tidak signifikan, $p=.18$. Body-image berperan secara signifikan terhadap penyesuaian diri pada kelompok partisipan yang memiliki usia kandungan berada pada trimester III dengan nilai, $R^{2}=.29, p=.001$.Sedangkan pada kedua kelompok partisipan yang memiliki usia kandungan trimester I $(p=.98)$ dan II $(p=.28)$, body-image tidak berperan secara signifikan terhadap penyesuaian diri.

\section{DISKUSI}

Di dalam penelitian ini, kami meneliti peran body-image terhadap penyesuaian diri para perempuan usia dini yang sedang mengalami kehamilan pertama. Kami berhipotesis bahwa body-image atau penilaian individu yang baik terhadap tubuhnya akan diiringi dengan penyesuaian diri terhadap masa kehamilan yang baik pula. Sesuai dengan hipotesis yang kami ajukan, peningkatan body-image diiringi oleh peningkatan penyesuaian diri. Dengan demikian, body-image memiliki peran penting dalam proses penyesuaian diri pada perempuan usia dini yang sedang mengalami kehamilan.

Hasil ini sesuai dengan pernyataan yang dikemukakan oleh Schneiders (dalam Ali \& Anshori, 2004) bahwa body-image akan memperani penyesuaian diri seseorang. Hal ini juga sesuai dengan pendapat Baron dan Byrne (2000) yang menyatakan bahwa seseorang yang memiliki kepuasan body-image diharapkan cenderung memiliki konsep diri yang positif, dengan konsep diri yang positif, seseorang akan mudah menjalani hidupnya, tampil lebih percaya diri, dan lebih asertif. Bagi wanita, konsep diri secara khusus didasarkan pada body-image dan sebagai konsekuensinya, hal ini memperani fungsi sosial dan hubungan interpersonal, yang pada akhirnya dapat menentukan bagaimana penyesuaian diri mereka (Rubin, 2005).

Ferron (1997) juga menyatakan bahwa tingkat kemampuan individu dalam menyesuaikan diri dengan perubahan tubuh berhubungan dengan kemampuan individu mengatasi kesulitan hubungan personal akibat perubahan tersebut. Selain itu hasil penelitian ini juga memperkuat hasil penelitian sebelumnya yang dilakukan oleh Da Pietro (Rubin, 2005), yaitu body-image yang positif berhubungan dengan perasaan positif terhadap kehamilan secara umum. Hal ini juga diperkuat oleh hasil penelitian Sheena (2004) bahwa orang yang memiliki body-image positif akan merasa percaya diri, merasa cantik dan menarik, mampu mengekspresikan perasaannya, mampu menyesuaikan dirinya dengan orang lain, serta menghargai tubuhnya sendiri dan orang lain.

\section{KESIMPULAN DAN SARAN}

\section{Kesimpulan}

Kesimpulan yang dapat ditarik dari penelitian yang telah dilakukan yaitu :

1. Body-image berperanpenting terhadap penyesuaian diri wanita dewasa dini pada kehamilan pertama. Semakin tinggi body-image, semakin tinggi pula penyesuaian diri terhadap kehamilan. 
2. Body-image berperan secara signifikan terhadap penyesuaian diri wanita dewasa dini pada kehamilan pertama pada wanita berusia 26-30 tahun, namun tidak pada kelompok usia 20-25 tahun dan usia 31-35 tahun.

3. Body-image berperan secara signifikan terhadap penyesuaian diri partisipan yang bekerja, namun tidak pada kelompok yang tidak bekerja.

4. Body-image berperan secara signifikan terhadap penyesuaian diri pada kelompok subjek yang memiliki usia kandungan berada pada trimester III, namun tidak pada partisipan yang memiliki usia kandungan pada trimester I dan II.

\section{Saran}

\section{Bagi penelitian selanjutnya}

Dari hasil penelitian diketahui bahwa body-image memberi sumbangan sebesar $20 \%$ terhadap penyesuaian diri wanita pada kehamilan pertama. Sisa $80 \%$ diperani oleh faktor lain yang dalam penelitian ini tidak diteliti. Bagi penelitian selanjutnya, peneliti menyarankan untuk melihat peran dari faktor lain tersebut, seperti perkembangan dan kematangan, faktor psikologis, kondisi lingkungan, serta aspek budaya dan agama terhadap penyesuaian diri wanita dewasa dini pada kehamilan pertama.

\section{Bagi wanita hamil pertama}

Agar wanita yang sedang hamil untuk pertama kalinya lebih banyak belajar dan mencari informasi tentang proses dan perubahan-perubahan, baik fisik maupun psikologis yang akan dialami selama hamil, sehingga wanita hamil akan lebih merasa nyaman dan bahagia menjalani kehamilannya.

\section{Bagi keluarga}

Sebaiknya keluarga, memahami kondisi wanita hamil terkait dengan body-image. Hal ini perlu dilakukan karena body-image akan memperani penyesuaian diri wanita selama masa kehamilan, yang pastinya akan memberikan keuntungan bagi wanita dan bayi yang dikandungnya.

\section{Bagi masyarakat}

Agar masyarakat lebih memperhatikan kondisi body-image dan penyesuaian diri wanita hamil, khususnya wanita yang sedang hamil pertama. Masyarakat dapat memberi informasi tentang kehamilan terkait body-image dan penyesuaian diri dengan akurat. Hal ini diharapkan agar wanita hamil dapat menjalani kehamilannya dengan perasaan tenang dan senang.

\section{REFERENSI}

Ali, M.,\& Anshori, M. (2004). Psikologi remaja: Perkembangan peserta didik. Jakarta: Bumi Aksara.

Astuti, A., Santosa, \& Utami. (2000). Hubungan antara dukungan keluarga dengan penyesuaian diri perempuan pada kehamilan pertama. Jurnal Psikologi.

Baron \& Byrne. (2000). Social psychology. New York: Mc Graw Hill.

Cash, T. F. (1999). Body-images, development, deviance, and change. New York: The Guilford Press.

Dacey, J. \& Kenny, M. (2001). Adolescent development $\left(2^{\text {nd }}\right.$ ed). USA: Brown \& Benchmark Publishers. 
Effendi, R.W., \& Tjahjono, E. (1999). Hubungan antara perilaku coping dan dukungan sosial dengan kecemasan pada ibu hamil anak pertama. Anima Indonesian Psychology Journal.

Ferron, C. (1997). Body-image in adolescence: Cross cultural research-result of the preliminary phase of a quantitative survey. Journal of Adolescence, (46), 115-123.

Kartono, K. (1995). Psikologi wanita. Bandung: Alumni.

Matlin, M., W. (2004). The psychology of women $\left(5^{\text {th }}\right.$ ed). California: Wadsworth.

Mochtar, M. (1998). Sinopsis obstetri dan ginekologi. Jakarta: Rineka Cipta.

Newman, B. M. \& Newman, P. R. (2006). Development through life: a Psychological approach $\left(9^{\text {th }} e d\right)$. California: Thompson Wadsworth.

Robertson-Frey,T. L. (2005). Body-image and pregnancy: application of the theory of reasoned action (Thesis). Saskaton: University of Saskatchewan. [On-line]. (www.proquest.com). Tanggal akses 9 Februari 2009.

Rubin. L. R. (2005). Eating for two: body-image among first time pregnant woman (Dissertation). Arizona: Arizona State University. [On-line]. (www.proquest.com). Tanggal akses 3 Februari 2009.

US Fed News Service. (2008, 8 Sep). Exercise helps with body-image, depression in pregnancy. [OnLine]. (www.proquest.com) tanggal akses 3 Februari 2009.

Santrock, J. W. (2001). Adolescence: perkembangan remaja (Edisi ke-6). Jakarta: Penerbit Erlangga.

Sheena, E., T. (2004). Body dissatisfaction of adolescent girls and boys. Journal of Early Adolescence, 23(2), 141-165.

Thompson, K.J. (1996). Body-images, Eating Disorder, and Obesity: An Integrative Guide for Assessment and Treatment. Washington, DC: American Psychological Asociation.

US Fed News Service. (2008, 8 Sep). Exercise helps with body-image, depression in pregnancy. [OnLine]. (www.proquest.com) tanggal akses 3 Februari 2009. 